\title{
Los múltiples rostros de la filosofía de la información
}

\author{
Olimpia Lombardi ${ }^{1}$ \\ Universidad de Buenos Aires (Argentina) \\ Consejo Nacional de Investigaciones Científicas y Técnicas (CONICET) \\ Theiss Research (EE. UU) \\ Cristian López ${ }^{2}$ \\ Universidad de Buenos Aires (Argentina) \\ Consejo Nacional de Investigaciones Científicas y Técnicas (CONICET)
}

Recibido: mayo 17 de 2016. Revisado: mayo 27 de 2016. Aceptado: mayo 31 de 2016

Referencia formato APA: Lombardi, O. \& López, C. (2016). Los múltiples rostros de la filosofía de la información. Rev. Guillermo de Ockham, 14(2), 21-32. doi: http://dx.doi.org/10.21500/22563202.2432

\section{Resumen}

La filosofía de la información ha experimentado en la un enorme auge en los últimos años y se ha consolidado como un ámbito de indagación filosófica autónomo. El concepto de información -tema de estudio de la filosofía de la información- es uno de los más extendidos en nuestros días y abarca esferas tan disímiles como el lenguaje cotidiano y la mecánica cuántica. Esta presencia ubicua y universal conduce a que su análisis y abordaje filosóficos sean empresas complejas y desafiantes. El presente artículo pretende ofrecer algunas líneas generales que permitan distinguir diferentes tipos de información, enfoques y contextos en los cuales el concepto es utilizado e interpretado de diversas maneras. De este modo, se muestra que la filosofía de la información es un área diversa y plural en la que el concepto de información reviste tantos significados, como usos y contextos.

Palabras clave: Información, filosofía, conocimiento, significado

\section{Multiple Faces of the Philosophy of Information}

\section{Abstract}

The philosophy of information is at its height nowadays. During the last years, it has grown stronger as an autonomous field of philosophical analysis, mainly concerned with the concept of information. 'Information' is currently one of the most common and spread out terms, one that is present across several domains, from everyday language to quantum mechanics. Due to its ubiquitous presence and wide extension, addressing the concept of information philosophically constitutes a challenging and thorny enterprise. This paper is aimed at providing some guidelines so as to distinguish different kinds, approaches, contexts and interpretations of information. Thereby, it is shown that philosophy of information is a highly diverse and plural field, in which information meets as many meanings as uses or contexts.

Keywords: Information, philosophy, knowledge, meaning

1. Universidad de Buenos Aires, Conicet y Theiss Research. Doctora en Filosofía e ingeniera en electrónica. Directora del Grupo de Filosofía de las Ciencias de la Universidad de Buenos Aires. Correo electrónico: olimpifilo@arnet.com.ar. Dirección postal: Crisólogo Larralde 3340, 6 D (1430), Ciudad Autónoma de Buenos Aires, Argentina.

2. Universidad de Buenos Aires y becario doctoral de Conicet. Licenciado en Filosofía. Miembro del Grupo de Filosofía de las Ciencias de la Universidad de Buenos Aires. Correo electrónico: lopez.cristian1987@gmail.com 


\section{Os múltiplos faces da filosofia da informação}

\section{Resumo}

A filosofia da informação tem experimentado um crescimento enorme nos últimos anos e se estabeleceu como um dominio da investigação filosofica autónoma. O conceito de informação -Item da filosofia da informação- é um dos mais extensos em nossos dias e abrange áreas tão diversas como a linguagem de todos os dias e a mecânica quântica. Esta presença ubíqua e universal leva a que seu análise e abordagem filosofico são empresas complexas e desafiantes. O presente artigo visa fornecer algumas orientaçóes gerais que permitem distinguir os diferentes tipos de informações, abordagens e contextos em que o conceito é utilizado e interpretado de diferentes maneiras. Assim, mostra-se que a filosofia da informação é uma área diversa e plural na que o conceito da informação mostra significados, usos e contextos.

Palavra-chave: Informação, filosofia, conhecimento, significado

\section{Introducción}

En los últimos años, una importante rama sui generis de la filosofía ha surgido, crecido en interés y ha consolidado en la comunidad filosófica: la filosofía de la información. En nuestras sociedades modernas fuertemente influenciadas por las tecnologías comunicacionales, aparatos digitales y medios masivos de comunicación, el concepto de información se ha vuelto central en disímiles esferas de nuestras vidas y permeado tanto el discurso cotidiano como el discurso científico. La filosofía de la información ha desembarcado en la comunidad filosófica como un campo autónomo de indagación y análisis del concepto de información para abarcar su ubicua presencia y elucidar su uso en ámbitos más específicos, fundamentalmente científicos.

Presente en la mayoría de las ciencias naturales y sociales, es en el ámbito científico donde el concepto ha ganado mayor precisión, riqueza y diversificación. Así, en mecánica cuántica la noción de "información cuántica" no solo ha revolucionado el campo tecnológico sino que también ha reavivado viejos problemas teóricos que ahora vistos desde una nueva óptica (Jozsa, 1998); en ecología, el concepto es básico en las mediciones de la diversidad ecológica de un ecosistema (Burnham y Anderson, 1998); en genética es fundamental cuando se formula en relación con la información genética, esencial en el proceso de herencia (Godfrey-Smith y Sterelny, 2016). En consonancia con esta diversificación y enriquecimiento, la filosofía de la información ha extendido su ámbito de influencia a subdisciplinas filosóficas como la filosofía de la física, la filosofía de la biología, la filosofía de las ciencias cognitivas, la ética, la lógica, etc.

La diversificación, precisión y extensión del concepto en campos tan disímiles (como la vida cotidiana y la teoría cuántica de la información) condujo a que una elucidación unívoca del concepto sea compleja y ardua. Las primeras pregunta filosóficas relevantes son socráticas: ¿qué es la información?, ¿cuál es su naturaleza?, ¿̇efiere a alguna entidad o sustancia en el mundo, o por el contrario, es un mero flatus vocis sin referencia? Si se hace hincapié en la diversidad y especificidad de sus diferentes usos y definiciones, ¿̨cómo vincular las diferentes "informaciones" presentes a lo largo y ancho del espectro científico y no científico? ¿Todas ellas refieren a lo mismo o cada una es irreconocible frente a la otra? A primera vista, analizar filosóficamente el concepto de información e intentar responder estas preguntas puede no solo ser agobiante sino también inasequible: ¡cómo abarcar de manera sistemática un concepto tan polimórfico y polisemántico? La ubiquidad del concepto parece conllevar su intangibilidad y con ella su inaprehensibilidad.

Sin embargo, la evidente pluralidad de sentidos del término información que se obtiene al enfrentar el panorama completo no es usualmente reconocida en la bibliografía, fundamentalmente en aquella abocada a esclarecer el concepto de información en ámbitos específicos que luego extrapola a otros. Autores como Wheeler (1990) y Davies (2014), han hecho de la información "la sustancia fundamental a partir de la cual toda la realidad es construida" (Davies 2014, p. 75), y sostienen una suerte de spinozismo informacional que privilegia una interpretación física fuerte del concepto de información.

Otros autores han utilizado la información algorítmica como base de una realidad en la que "el universo es una computadora que computa” (Lloyd 2014, p. 96). Por otra parte, prácticamente de manera unívoca, la teoría matemática de la comunicación de Shannon (formulada por Claude Shannon en 1948) ha sido el formalismo privilegiado a la hora de lidiar con problemas que involucran transmisión de información. Si bien está diseñado para problemas ingenieriles en el área de la comunicación, la teoría de Shannon ofreció un formalismo tan poderoso 
que no solo fue rápidamente extrapolado a otros ámbitos, sino que también se convertiría en teoría para resolver problemas conceptuales concretos; por ejemplo, en el ámbito de la genética se buscó utilizar la información de Shannon para elucidar y definir el concepto de información genética (Bergstrom y Rosvall, 2011).

El objetivo de este artículo es ofrecer un primer ordenamiento del vasto y variado campo de la filosofía de la información. Para ello, articularemos una serie de distinciones de enfoques, contextos e interpretaciones que resultarán útiles no sólo para recoger los diferentes sentidos en los cuales se habla de información, sino también para delimitar el alcance y límites de definiciones y teorizaciones específicas. Particularmente, mostraremos que las teorías formales de la información, en especial la teoría de Shannon, no son capaces de ofrecer una definición unívoca del concepto de información sino que, por el contrario, encierran una variedad de sentidos y matices que deben ser distinguidos.

\section{Primeros acercamientos al concepto de información: información cotidiana frente a información técnica}

Como señala Floridi (2016), la información es un fenómeno polimórfico y polisemántico. En la Antigüedad, fundamentalmente en los textos de Aristóteles y Platón, el concepto de información estaba fuertemente vinculado a categorías epistémicas y ontológicas derivadas del concepto helénico de eidos" (Adriaans y van Benthem 2008; Adriaans 2013). Sin embargo, el concepto solo tuvo un uso técnico y marginal hasta mediados del siglo XX cuando experimentó un abrupto crecimiento tanto en el discurso científico como en el cotidiano. Probablemente, la revolución digital, el vertiginoso desarrollo de las comunicaciones y la hegemonía de los medios de comunicación sean responsables de la masificación y universalización del término.

En un primer acercamiento intuitivo, el concepto de información parece estar relacionado con la transmisión y el almacenamiento de datos: la información está constituida por datos que son transmitidos y almacenados. Por ejemplo, cuando hacemos una compra por internet, intuitivamente entendemos a qué se refiere una página cuando nos pide que ingresemos información acerca de nuestra dirección, fecha de nacimiento o tarjeta de crédito; brindamos los datos correspondientes a cada campo que luego serán transmitidos al servicio de venta para finalizar la compra. Sin embargo, el concepto mismo de dato es filosóficamente oscuro, ya que también tiene un enorme rango de aplicaciones posibles y su significado varía de contexto a contexto. Por un lado, puede ser interpretado epistémicamente como los datos que nos brindan los sentidos a partir de los cuales es posible el conocimiento (esto, si se asume una interpretación moderna y empirista de la noción de dato); o bien puede ser interpretado computacionalmente como una mera secuencia de símbolos no interpretados (Floridi, 2016).

Otra manera de aproximarnos general e intuitivamente a la noción de información es mediante el concepto de conocimiento, en el sentido de algo que brinda o genera conocimiento. Si bien más adelante desarrollaremos interpretaciones técnicas particulares que recurren a la idea de conocimiento para elucidar el concepto de información, nuestro uso cotidiano del vocablo parece revelar este vínculo subyacente. En sociedades altamente tecnificadas como las nuestras en las que el acceso al conocimiento está fundamentalmente dado por diversos medios de comunicación (internet, televisión, diarios, revistas, etc.), un concepto abstracto de masa que designe ese flujo de datos capaz de transmitir y producir conocimiento es sumamente útil (Adriaans, 2013).

Timpson $(2004,2013)$ denomina everyday information o information al tipo de información que utilizamos cotidianamente e involucra nociones como significado, conocimiento o representación. Sin embargo, de acuerdo con Timpson hay otro tipo de información (technical information o information), que no involucra tipo alguno de dimensión semántica y epistémica: la información usualmente utilizada en disciplinas formales o científicas. El propósito de Timpson es prevenir cualquier confusión entre ambos tipos de información y evitar la elucidación de un concepto mediante el otro. Sin embargo, más allá de este motivo -que puede o no ser compartido- una primera manera de ordenar el campo de la filosofía de la información puede basarse en distinguir entre una información asociada a nociones como significado, verdad/ falsedad o conocimiento y generalmente basada en nuestro uso del término en el lenguaje natural, y una información no semántica o matemática que ha experimentado una extraordinaria diversificación y precisión en el ámbito científico. Esta distinción estaría dada por dos enfoques respecto del concepto de información: el enfoque semántico y el enfoque no semántico o formal.

Ambas visiones han tenido -y tienen- un desarrollo relevante en la filosofía en general, aunque en direcciones diferentes: mientras el enfoque semántico busca esclarecer el concepto de información semántica involucrado en el 
lenguaje natural mediante la lógica y la filosofía del lenguaje (Bar-Hillel, 1964; Devlin, 1991) o en sus influencias éticas (Floridi, 2015), el enfoque no semántico o formal atiende la manera como el concepto de información matemática es utilizado y conceptualizado en las diversas teorías formales de la información. Asimismo, es el enfoque más utilizado en la ciencia y en la filosofía de la ciencia (la filosofía de la física, la filosofía de la computación o la filosofía de la biología).

A pesar de ser significativa y útil a la hora de especificar dos tipos distintos de información, no cabe determinar que los enfoques suponen una separación absoluta entre ambos: el enfoque matemático de la información, si bien primariamente interesado por los aspectos y las propiedades formales del concepto de información, no excluye por completo toda dimensión semántica; y, por supuesto, el enfoque semántico tampoco excluye todo tratamiento formal. La distinción tiene que leerse como un primer punto de bifurcación en dos direcciones distintas de aquella aproximación intuitiva ofrecida al inicio de esta sección. En la sección siguiente seguiremos una de esas direcciones, a saber, el concepto de información semántica, y se presentarán de manera general algunas de sus características principales y problemas.

\section{Información semántica: significado, representación y verdad}

El concepto de información semántica es cada vez más central en esferas como la lógica, la filosofía del lenguaje, la filosofía de la mente o la ética. Probablemente sean Rudolf Carnap, Joshua Bar-Hillel y Luciano Floridi los representantes que más han impulsado y desarrollado el enfoque semántico.

Uno de los primeros trabajos sistemáticos sobre el concepto de información semántica es el artículo de Bar-Hillel y Carnap (1953) en el cual se busca delimitar el campo de aplicación y el estudio de la información semántica desde un punto de vista lingüístico y lógico. Luego de reconocer el éxito práctico de la teoría matemática de la comunicación de Shannon (1948), los autores denuncian el paso en falso dado por

científicos impacientes de varios campos [que] aplicaron la terminología y los teoremas de la teoría de la comunicación a campos en los cuales el término 'información' fue usado, de manera presistemática, en un sentido semántico, es decir, involucrando el contenido de símbolos e, incluso, su uso pragmático (Bar-Hillel Carnap, 1953, p. 147).
El punto de inflexión, de acuerdo con Bar-Hillel y Carnap, entre dos "sentidos" de información, radica en que mientras la información utilizada en diversas teorías formales solo se ocupa de mediciones de cadenas de símbolos o su frecuencia de ocurrencia, la información semántica se interesa en el contenido mismo de los símbolos. "Frecuentemente los mensajes tienen significado; es decir, ellos refieren o están correlacionados con algún sistema conformado por ciertas entidades físicas o conceptuales. Estos aspectos semánticos de la comunicación son irrelevantes para los problemas de ingeniería" (Shannon, 1948, p. 379. Cursivas del original).

Parece claro que a simple vista un abordaje sistemático del concepto de información semántica busca analizar esta dimensión, la cual involucra nociones como significado, verdad y falsedad, representación, etc., dimensión no considerada -al menos prima facie- por un enfoque estadístico o formal de la información.

Floridi (2016) parte de elucidar el concepto de información semántica mediante la noción de dato: según el autor, $x$ es una instancia de información semántica si $y$ solo si $x$ consiste en uno o más datos; los datos en $x$ están bien formados y los datos bien formados en $x$ son significativos. En esta definición, la noción de dato es entendida en términos de falta o pérdida de uniformidad en algún contexto, ya sea en el mundo real o en el simbólico. Sin embargo, esta definición basada en la noción de dato no es universalmente aceptada, pues otros autores han preferido adoptar una concepción semiótica de la información (Nauta, 1972) o una concepción pragmática (Fetzer, 1990).

El punto de partida para un análisis del concepto semántico de información son las oraciones del lenguaje natural, las cuales llevan información y pueden (o no) ser informativas. De manera general, cuando decimos que " $x$ tiene información acerca de $y$ ", decimos que " $x$ representa o significa $y$ ". Cuando expresamos que una oración es informativa, nos referimos a que posee información respecto de algo, ya sea un estado de cosas en el mundo, algún ítem lingüístico o un estado mental que queremos comunicar. Un aspecto central de la información semántica es su aboutness; es decir, su "referencia a algo", su carácter intencional. De esta manera, cuando afirmamos “está lloviendo a cántaros afuera”, mediante esa oración bien formada del español estamos informarndo a nuestro interlocutor acerca de un estado del mundo en particular: afuera está lloviendo. Sin embargo, cuando leemos una receta de cocina y obtenemos información sobre cómo hacer un carrot cake, no parece que estuviésemos lidiando 
con el mismo tipo de información. Entonces, ¿`cuál es la diferencia entre ambas?

La información semántica parece susceptible de ser interpretada como información factual o información instruccional. La información semántica factual generalmente está involucrada en oraciones declarativas del lenguaje y puede ser verdadera o falsa. "Está lloviendo afuera" es una oración que será verdadera si efectivamente llueve afuera, o falsa si el sol está brillando y el tiempo es seco. Por el contrario, la información semántica instruccional es la clase de información que encontramos en recetas de cocina, instructivos, oraciones imperativas del lenguaje, etc. En este caso, la información semántica implicada no representa estado de cosa alguno, sino que busca producirlo. “¡No pisar el pasto!” o "agregue $500 \mathrm{~cm}^{3}$ de leche y luego mezcle lentamente" son oraciones que contienen información semántica de tipo instruccional y persiguen obtener un resultado concreto, como es mantenernos fuera del pasto en el primer caso e instruirnos acerca de cómo hacer una comida en el segundo. La información semántico-instruccional no es verdadera ni falsa, ya que sería absurdo preguntarse por el valor de verdad del imperativo "¡no pisar el pasto!"; sin embargo, califica como información semántica ya que es una oración interpretable y significativa del lenguaje natural. Como en el caso de los poemas o la música, la información semánticoinstruccional " aun cuando esté compuesta en el lenguaje de la información, no es usada en el juego del lenguaje de dar información" (Wittgenstein, 1981).

Dentro de la información semántica, la información semántica factual ha recibido mayor atención y análisis, en particular por su estrecho vínculo con el concepto de verdad. Obviamente hay oraciones del lenguaje natural verdaderas o falsas, aunque no hay claridad sobre cómo considerarlas desde un punto de vista informacional. Cuando afirmamos que el testigo brindó información verdadera acerca del escondite del secuestrador, es porque declaró que el secuestrador se encontraba en el lugar $x \mathrm{y}$, efectivamente, el secuestrador estaba allí. En virtud de que las oraciones del testigo eran verdaderas, la información brindada acerca de un hecho (en este caso el escondite del secuestrador) es verdadera.

El problema surge cuando se interpreta informacionalmente oraciones falsas. Por ejemplo, "el testigo dio información falsa acerca del escondite del secuestrador", supone que las oraciones que el testigo pronunció resultaron falsas en función de no representar el verdadero escondite del secuestrador. Pero, ¿en qué sentido oraciones falsas de este tipo resultan informativas? El testigo, ¿nos dio algún tipo de información? Dicho de otra manera, ¿solo la información verdadera puede calificar como información? Fetzer (2004), mediante un enfoque débil de información semántica, argumenta que no necesariamente toda información tiene que ser verdadera para contar como tal. De ser así, no deberíamos considerar como informacional cualquier oración imperativa del lenguaje, desechando así la noción misma de información instruccional. Por otro lado, el concepto mismo de "información falsa” parece ser significativo y pragmáticamente exitoso a la hora de hacer distinciones relevantes (Fetzer, 2004). Por su parte, Floridi (2003) sostiene un enfoque de información semántica según el cual solo la información verdadera debe ser considerada como información, ya que la información "encapsula la verdad". En consonancia con Floridi, Dretske (1981) afirma que "la información falsa y la información errónea no son clases de información, no más que los patos ornamentales y los patos de goma son clases de patos" (p. 45). Por lo tanto, un enfoque débil de la información semántica (como el sostenido por Fetzer) sostendría que existe cierta neutralidad aléthica respecto de la información semántica en la que datos significativos y bien formados califican como información. Por el contrario, defensores de un enfoque fuerte semántico de la información (Floridi o Dretske), sostendría que esta no solo consiste de datos significativos y bien formados, sino que además deben ser datos verídicos.

Otro de los problemas centrales de la información semántica es elucidar su relación con la noción de conocimiento. Intuitivamente, consideramos que si obtengo información acerca de $p$, entonces conozco algo acerca de $p$. Esta intuición probablemente se basa en dos ideas detrás de la noción de información: por un lado, en un resabio de la metodología y la teoría del conocimiento empirista que construye a posteriori los conceptos (y el conocimiento mismo) en la mente a partir de impresiones o datos sensibles (Adrian's, 2013); y por otro lado, en la idea de que la información es reducción de incerteza. Este pensamiento ha sido desarrollado tanto en el ámbito de la información matemática, como en el de la información semántica. La intuición apunta a que cuanto más información obtenemos sobre algo, tanto más aumenta nuestro conocimiento y se reduce la incerteza acerca de ese algo. Como sostiene Adriaans (2013), cuando tenemos absoluta certeza sobre un estado de cosas, no podemos recibir nueva información acerca de él.

El vínculo entre información semántica y conocimiento también ha sido abordado en el sentido de información ambiental. Algunas teorías filosóficas de la información pretenden fundamentar contenidos factuales semánticos 
en términos de la información que el ambiente proporciona a un agente que interactúa con él (Dretske, 1981; Barwise y Seligman, 1997). De esta manera, se dan relaciones epistémicas entre el observador (que obtiene información a partir de lo observado) y el ambiente.

\section{Información matemática: teorías formales de la información, contextos e interpretaciones}

La distinción entre información semántica e información matemática es sumamente útil, pero es solo el primer paso en el camino a ofrecer significados más específicos del concepto de información. La noción de información matemática, a diferencia de lo que podría suponerse, despliega un campo de estudio variado y polimórfico. Diversas teorías formales desarrolladas en las últimas décadas se han utilizado en diferentes contextos y han propuesto diferentes definiciones del concepto de información. Por lo tanto, la mera asunción de un enfoque no semántico solo permite establecer algunos límites y alcances de la información matemática sin lograr una definición clara y precisa del concepto. Para ello, es necesario llevar a cabo ulteriores distinciones dentro del concepto.

Para mostrar las variedades y matices que conviven en relación con este concepto, se deben distinguir, en primera instancia, dos contextos en los que el concepto es empleado, a saber, un contexto computacional y un contexto comunicacional. Si bien ambos utilizan una noción matemática y no semántica de información, el tipo de información matemática que se obtiene de ellos no es equivalente. Ulteriormente, señalaremos que incluso dentro de cada contexto el concepto de información sigue siendo vago e impreciso hasta no ser interpretado. De esta manera, distinguiremos al menos tres interpretaciones que pueden asumirse de la información matemática, y nos centraremos en el contexto de la comunicación en el cual la célebre teoría de Shannon ha sido desarrollada.

\section{Información algorítmica en contextos computacionales}

En un contexto computacional, la información es básicamente algo que puede ser computado y almacenado y en este sentido las diferentes teorías de la información en contextos computacionales buscan hacerlo de una manera eficiente. La teoría de la complejidad algorítmica de Solomoff (1964), Chaitin (1966) y Kolmogorov $(1965,1968)$, utiliza la noción de complejidad algorítimica o de Kolmogorov como una medida de los recursos necesarios para reconstruir eficientemente un mensaje individual. En esta dirección, la teoría provee una medida de la información que cada mensaje individual posee, independientemente de la fuente que lo produce o de cómo sea transmitida. La teoría de la complejidad algorítmica, por lo tanto, se preocupa por determinar la tasa máxima de compresión de mensajes individuales, en la que esa compresión puede ser vista como contentiva de información de cierto tipo. La idea básica estriba en que algunos mensajes pueden ser comprimidos de manera considerable de si presentan con suficiente regularidad. Por lo tanto, la información algorítmica de un mensaje particular se define como el largo del programa más corto posible que produce el mensaje en una máquina de Turing.

Vale la pena remarcar un aspecto característico de la información algorítmica o computacional consistente en una propiedad predicable de mensajes individuales; es decir, se la puede definir en relación con un único mensaje. La información algorítmica no requiere una fuente que la produzca o un canal de transmisión, ni siquiera estar involucrada en un proceso comunicacional para ser definida. Probablemente, este sea el motivo por el cual algunos teóricos de la información, especialmente científicos de la computación, consideran que la información o complejidad algorítmica es más fundamental que otros tipos de información, como la definida por Shannon (Cover y Thomas, 1991) en la medida en que la complejidad kolmogoroviana asigna complejidad asintótica a un mensaje individual y prescinde de la noción de probabilidad (Cover y Thomas, 1991; Lombardi, Holik y Vanni, 2015).

\section{Información comunicacional: teorías matemáticas de la comunicación}

Cuando consideramos contextos comunicacionales, la información es entendida como algo que puede ser transmitido entre dos puntos del espacio con fines comunicativos. La teoría matemática de la comunicación de Shannon (1948) es el ejemplo paradigmático de una teoría formal que asume un enfoque puramente no semántico o estadístico de la información en un contexto comunicacional en el que "el problema fundamental de la comunicación es reproducir en un punto exacto o aproximadamente exacto, un mensaje seleccionado en otro punto" (Shannon, 1948, p. 379).

Una situación comunicacional puede ser muy compleja y disponer de una variedad considerable de elementos. No está entre las pretensiones de este trabajo ofrecer una definición de la comunicación ni un análisis filosófico de ella. Si bien la teoría formal de Shannon es el formalismo 
clásico que se utiliza en contextos comunicacionales, otros intentan capturar el concepto de información comunicacional desde diferentes perspectivas; por ejemplo, la información de Fisher (1925) o la entropía de von Neumann (Schumacher, 1995).

En términos generales, en toda situación comunicacional pueden identificarse tres elementos: una fuente, un canal y un destinatario. De manera abstracta, la fuente $S$ produce una cantidad de información $I(S)$ que será transmitida al destinatario $D$, el cual recibe una cantidad de información determinada, $I(D)$; la información es transmitida por un canal $C$ que vincula fuente y destinatario. Tanto $S$ como $D$ son sistemas con un rango de estados posibles cada uno con su propia probabilidad, y es en estos términos que se calcula la cantidad de información producida y recibida. Usualmente, la cantidad de información calculada es medida en bits, aunque puede utilizarse alguna otra unidad de medida (nats, por ejemplo). El canal $C$ se caracteriza por medio de probabilidades condicionales que vinculan la aparición de los estados de la fuente con la aparición de los estados del destinatario. Además, otras cantidades pueden definirse a partir de estos elementos, como la equivocidad (información generada en la fuente, pero no recibida en el recepto), el ruido (información recibida por la fuente, pero que no proviene de ella) y la información mutua (información generada en la fuente y recibida en el receptor), entre otras. Todas estas cantidades apuntan de una u otra manera, al éxito comunicativo.

La información comunicacional exhibe dos propiedades que la distinguen de la información algorítmica. Por un lado, la información comunicacional no es predicable de mensajes individuales sino de la fuente y el destinatario en una estructura comunicacional. El concepto de información comunicacional no sería definible sin apelar a los estados de la fuente, el destinatario y las correlaciones entre ellos. Por otro lado, si bien no explícito en las teorías formales de la comunicación, parece haber una cierta noción causal involucrada en toda situación comunicacional. Toda situación comunicacional requeriría que cierta acción llevada a cabo en la fuente modifique el estado del destinatario, de manera que el estado de la fuente pueda ser identificado en el destinatario.

\section{Diferentes interpretaciones: física, epistémica y deflacionista}

Mediante la distinción de contextos donde el término "información" es usado de diferentes maneras, hemos especificado al menos dos sentidos del concepto información. Conceptualmente, la información algorítmica y la información comunicacional solo delimitan diferentes campos de aplicación y diferentes usos del concepto técnico de información matemática. Las preguntas acerca de qué es la información, a qué refiere o cuál es su naturaleza y cuáles son sus propiedades siguen siendo tan válidas como antes.

Contrario a lo que suele suponerse, las teorías formales por sí mismas no son suficientes para fijar un significado unívoco y conceptualmente rico del concepto de información, razón por la cual la tarea de interpretar el concepto se vuelve sumamente necesaria. Es posible distinguir, al menos, tres interpretaciones: una interpretación epistémica, una interpretación física y una interpretación deflacionista. Mediante una interpretación del concepto de información, no solo es posible expedirse acerca de qué es la información, cuáles son sus propiedades, cuál es su referente, etc., sino que además las diferentes interpretaciones enfrentan o superan algunos problemas que no existen en las otras; por ejemplo, ciertas situaciones podrían ser consideradas comunicacionales o informacionales bajo una interpretación, mientras que bajo otra no lo serían.

\section{Interpretación epistémica}

En la segunda sección del artículo especificamos en qué consiste la información semántica. Allí mencionamos que usualmente estaba asociada a un contenido epistémico y a cambios en el estado de las creencias de las personas, de acuerdo con la información disponible. La información matemática también es susceptible de interpretación epistémica, aunque en este caso está vinculada a las teorías formales de la información y no al uso y las influencias del término información en el lenguaje natural.

Según la interpretación epistémica, la información "es un bien que, dado el receptor adecuado, es capaz de producir conocimiento" (Dretske, 1981, p. 47). Uno de los exponentes de la interpretación epistémica con soporte en la teoría formal de Shannon (con algunas modificaciones; ver Lombardi, 2005) es Dretske, quien sostiene que "un estado de hechos contiene información acerca de $x$ solo en la medida en que un observador adecuado pueda aprender algo acerca de $x$ consultándolo" (Dretske, 1981, p. 45). Desde este punto de vista, la información está siempre vinculada a un incremento en el conocimiento de la persona que la recibe. Autores como MacKay (1969), buscaron desarrollar una interpretación epistémica de la información matemática desvinculada de la teoría formal de Shannon. MacKay propuso una teoría cuantitativa de la información cualitativa conectada con la lógica de situación: "Supongamos que comenzamos preguntándonos qué queremos 
decir por información. En términos generales, decimos que hemos ganado información cuando ahora sabemos algo que no sabíamos previamente; es decir, cuando 'lo que sabemos' ha cambiado" (Mackay, 1969, p. 10).

La interpretación epistémica se ha extendido al ámbito de las ciencias físicas. En un libro de texto tradicional acerca de la teoría de Shannon aplicada a la ingeniería, se dice que la información "se mide como una diferencia entre el estado de conocimiento del receptor antes y después de la comunicación de la información" (Bell, 1957, p. 7). Entre los intentos de dar un fundamento informacional a la mecánica cuántica, Zeilinger (1999) sostuvo la igualdad entre información y conocimiento: "Tenemos conocimiento, i.e. información, de un objeto sólo a través de la observación" (p. 633).

Es importante subrayar que cuando se considera a la información de acuerdo con una interpretación epistémica, su transmisión no requiere una conexión física entre fuente y receptor; podría haber transmisión de información incluso sin la existencia de una señal portadora o de un canal físico. Sin embargo, las probabilidades que vinculan fuente y receptor no pueden ser meras correlaciones accidentales. Las probabilidades involucradas en el contexto comunicacional no son correlaciones de facto, sino manifestaciones de regularidades legaliformes subyacentes.

\section{Interpretación física}

A diferencia de la interpretación epistémica, la interpretación física de la información no vincula información con conocimiento. De acuerdo con ella, la información es una magnitud física, algo que puede ser generado en un punto del espacio físico y transmitido a otro punto; algo que puede ser acumulado, almacenado y convertido de una forma a otra (Rovelli, 1996). Uno de los exponentes que con más vehemencia ha defendido la interpretación física de la información es Landauer (1996), para quien

la información no es una entidad abstracta descorporizada; está siempre ligada a una representación física. Se representa grabando sobre una tabla de piedra, un espín, una carga, un agujero en una tarjeta, una marca sobre un papel o sobre alguna otra cosa equivalente (p. 88).

Usualmente, la interpretación física de la información se vincula con un conocido dictum: "No hay información sin representación. El manejo de información está limitado por las leyes de la física y por la materia disponible en el universo" (Landauer 1991, p. 29), lo que significa que la transmisión de información entre dos puntos del espacio físico siempre requiere una señal portadora; es decir, un proceso físico que se propague de un punto al otro del espacio. En virtud de la naturaleza física de la información, su dinámica está regida por las leyes de la física y los hechos.

La interpretación física de la información se apoya en las intuiciones y el punto de vista usual de los físicos e ingenieros en comunicación. Tradicionalmente, el principal interés de la ingeniería en comunicaciones es optimizar la transmisión de información por medio de señales físicas, cuya energía y ancho de banda están restringidos por limitaciones tecnológicas y económicas. Para ello, los canales han de ser diseñados de tal modo que la transmisión de información tenga el mayor rendimiento posible. Es destacable que la capacidad del canal es medida en bits por segundo y en la medida en que la unidad de medida del flujo de información está vinculada mano a mano con las magnitudes físicas tradicionales, la tentación de considerar a la información como una magnitud física es difícil de evitar. Otros autores basados en el carácter físico de la información, han trazado su vínculo con el concepto de energía y argumentan que ambas magnitudes tienen el mismo estatus ontológico (Stonier, 1990, 1996).

\section{Interpretación deflacionista}

Si bien la interpretación física de la información es la usual en la comunidad de físicos e ingenieros y es generalmente asumida en los libros de texto, una interpretación deflacionista del concepto de información parece estar imponiéndose hoy en día. Algunos manuales técnicos actuales explican la teoría de la información de una manera absolutamente formal, sin referencia a fuentes, receptores, señales o canales. En su lugar, los conceptos básicos son introducidos mediante términos como variables aleatorias, distribuciones de probabilidad sobre valores posibles y correlaciones entre ellos (Cover y Thomas, 1991). Desde esta interpretación deflacionista, la información no tiene relación alguna con algún ítem físico del mundo ni con nociones como conocimiento o significado. La información solo tiene una dimensión sintáctica y la teoría de la información es un capítulo más de la teoría de la probabilidad (Reza, 1961).

En la comunidad filosófica, la interpretación deflacionista del concepto de información está motivada por los problemas que se siguen de adoptar una interpretación física o epistémica de la información. Timpson (2004, 2008 y 2013) y Duwell (2008) parecen seguir esta línea. De acuerdo con Timpson, "información" es meramente un término de masa abstracto que no tiene referencia. Asumida esta postura, problemas relacionados con el 
modo como la información es transmitida en ciertas situaciones comunicacionales se desvanecen automáticamente, ya que "información no es una sustancia o entidad que se transporte ni un término con referencia" (Timpson, 2008, p. 599).

Los argumentos que presenta Timpson para sostener su punto de vista deflacionista se basan en asumir que la teoría de la información de Shannon (sobre la que él centra su trabajo) permite establecer un concepto preciso de información. El punto de partida consiste en sostener que "información es lo que produce una fuente de información” (Timpson, 2013, p. 22), y en distinguir entre la secuencia concreta de estados que la fuente produce y el tipo de secuencia que se está instanciando. Esta distinción apela a la vieja distinción metafísica entre tipos y casos. Si una fuente de información produce una secuencia de estados $a, b, c, f, a, d, c, f$, lo que se quiere transmitir y reproducir en el destinatario no es esa misma secuencia de estados, sino otro caso del mismo tipo. Por lo tanto, lo que una fuente de información produce y lo que se quiere transmitir al destinatario es un tipo de secuencia de estados. Metafísicamente, los tipos son entidades abstractas, por lo tanto la información también lo es.

Bajo la interpretación deflacionista, el éxito comunicativo es definido en términos de un mapeo uno a uno entre los estados de la fuente y los del destinatario (Duwell, 2008); o en términos de similaridad estructural (Timpson, 2013). De esta manera, la transmisión de información dependería de las características formales de la situación comunicacional, independientemente de cómo esa situación y características son implementadas físicamente.

\section{Virtudes y limitaciones de las diferentes interpretaciones}

Si bien todas estas interpretaciones son igualmente compatibles con la teoría matemática de Shannon u otras teorías formales de la información, cuál de ellas asumir desde un punto de vista filosófico no es trivial. Al adoptar una de ellas no solo estamos identificando información con entidades de diferente naturaleza, sino que diferentes situaciones formalmente manejables a partir de una teoría matemática de la información podrían tener diferentes consecuencias conceptuales. De esta manera, cada interpretación no solo presenta ciertos beneficios o nos permite lidiar con ciertas situaciones informacionales de manera más natural y eficaz, sino que también enfrenta diferentes problemas, insuperables en algunos casos. Ninguna de estas interpretaciones está libre de problemas y todas ellas ofrecen algún tipo de ventaja en algún punto. Veamos esto con más detalle.

La ventaja más inmediata que ofrece la interpretación epistémica de la información es que permite recoger de una manera formal y sistemática, nuestras primeras intuiciones acerca del carácter epistémico y semántico de la información, con fundamento en teorías matemáticas bien establecidas y confiables. Esta interpretación hace posible un tratamiento cuantitativo y preciso de situaciones comunicacionales que involucran agentes que intercambian información y cambian sus creencias en función de ella, analizando cómo la información se transmite, se almacena y modifica nuestro estado de conocimiento. Sin embargo, otras situaciones parecen poner a la interpretación epistémica en aprietos, ya que considera comunicacionales situaciones que intuitivamente no lo son. Analicemos el siguiente ejemplo.

Supongamos una antena de televisión T que emite señales electromagnéticas y dos televisores $\left(\mathrm{TV}_{1}\right.$ y $\left.\mathrm{TV}_{2}\right)$ reciben esas señales. Si se considera la antena como fuente de información y los dos televisores como receptores, es posible definir los estados de cada uno con sus respectivas probabilidades y las correlaciones entre ellos, además de identificar la señal portadora de la información (las ondas electromagnéticas). En esta situación comunicacional, podemos establecer algunos vínculos y correlaciones de manera clara. Por un lado, existe una correlación entre los estados de $\mathrm{TV}_{1}$ y $\mathrm{TV}_{2}$ con los estados de la antena de transmisión $\mathrm{T}$, de manera que podemos conocer el estado de cualquiera de los dos televisores con solo conocer el estado de la antena (por ejemplo, al saber qué señal está emitiendo la antena T). Pero además, podemos identificar una correlación fuerte entre $\mathrm{TV}_{1}$ y $\mathrm{TV}_{2}$; mirando el estado de uno de los televisores podemos conocer, inmediatamente, el estado del otro. A pesar de no existir relación física entre ellos, nada nos impide desde el punto de vista formal, considerar uno como fuente y otro como receptor. Ahora bien, ¿existe genuina transmisión de información entre $\mathrm{TV}_{1}$ y $\mathrm{TV}_{2}$ ? Apelar al mero formalismo no facilita las cosas, ya que utilizando, por ejemplo, la teoría formal de Shannon, nada nos impediría tratar esta relación como informacional. En este punto resulta necesario recurrir a las interpretaciones.

Intuitivamente, pensaríamos que no hay transmisión de información entre $\mathrm{TV}_{1}$ y $\mathrm{TV}_{2}$, y esta intuición es recogida por la interpretación física de la información. La ausencia de un vínculo físico (un canal o señal portadora de la información) entre ambos televisores no nos permite hablar con sentido de transmisión de información en este caso. 
Sin embargo, si asumimos una interpretación epistémica de la información, la inexistencia de un vínculo físico no es argumento para negar la transmisión de información. En efecto, es posible aprender algo acerca de $\mathrm{TV}_{1}$ con solo mirar $T_{2}$ y viceversa. Por lo tanto, deberíamos admitir que hay transmisión de información. "Si las relaciones estadísticas que definen equivocidad y ruido entre $S$ y $\mathrm{R}$ son apropiadas, entonces hay un canal entre esos dos puntos, y hay información entre ellos, aunque no haya un vínculo físico directo entre $S$ y R" (Dretske, 1981, p. 38). Un problema similar enfrenta la interpretación deflacionista de la información.

Un punto central al referirnos a la comunicación parece fundarse en diferenciar entre genuinas situaciones comunicacionales y meras correlaciones. Tanto la interpretación epistémica como la interpretación deflacionista no disponen de recursos conceptuales para establecer esta distinción con claridad. Por su parte, la interpretación física sí permite llevar a cabo esta distinción, ya que la existencia de un canal físico y una señal portadora es central para ello. No hay transmisión de información sin canal ni señal portadora de la información.

Sin embargo, la interpretación física de la información no está exenta de problemas y, curiosamente, estos aparecen en el ámbito de las ciencias físicas, en particular la mecánica cuántica. En las últimas décadas, la emergencia de un nuevo tipo de información, a saber, la información cuántica, ha revolucionado el campo. Usualmente se considera que el trabajo de Schumacher (1995), es la formulación precisa de una teoría de la información cuántica. Una de las ventajas de esta información es la posibilidad de transmitir información sin la necesidad de un canal físico sino mediante el llamado protocolo de teleportación cuántica. Esta consiste en transmitir cierta cantidad de información cuántica haciendo uso del fenómeno cuántico de entrelazamiento (la descripción del protocolo puede encontrarse en cualquier texto sobre el tema. Ver Nielsen y Chuang, 2010). La idea es que una cantidad muy grande información (estrictamente infinita) puede transferirse de Alice a Bob enviando solamente dos bits mediante un canal clásico. Sin embargo, es claro que no existe un canal cuántico mediante el cual la información contenida en el estado cuántico pueda transmitirse.

Si la interpretación física de la información era adecuada para lidiar con casos que involucran antenas de transmisión y televisores y distinguía meras correlaciones de situaciones comunicacionales genuinas, el requerimiento de un canal físico puede ser una exigencia demasiado fuerte para pugnar con casos como la teleportación cuántica. Desde el punto de vista de la física y la ingeniería, intuitivamente parece haber una genuina transmisión de información en el protocolo de teleportación; sin embargo, la ausencia de un canal físico mediante el cual la información cuántica se transmita, no permite identificarlo como un caso genuino de comunicación y transmisión de información desde una interpretación física. Desde un punto de vista deflacionista, el problema se disuelve de manera automática en cuanto no hay nada (sustancia) que sea transmitida en el protocolo de teleportación. Tampoco hay problema respecto del protocolo de teleportación cuando es abordado a partir de una interpretación epistémica. Lo único que interesa desde este punto de vista es cómo los estados de conocimiento de Alice y Bob cambian en una situación comunicacional en la que un tipo de información es enviada, transmitida y recibida sin considerar si existe o no un canal físico involucrado.

\section{Comentarios finales}

La filosofía de la información está en pleno desarrollo en todas sus ramificaciones y extensiones. El presente artículo ha buscado sistematicidad al abordar los principales problemas conceptuales, ontológicos y epistémicos que presenta el concepto de información cuando es indagado filosóficamente. En general, se ha mostrado que a lo largo de todas sus diversificaciones, usos, contextos e interpretaciones, no existe un único concepto de información sino que varios de ellos conviven, todos útiles y efectivos, bajo diferentes enfoques o contextos. En primera instancia, el trabajo buscó mostrar dos tipos generales de información cuando el concepto es analizado desde diferentes enfoques: una información semántica y una información matemática. En un segundo paso y centrados en la información matemática, distinguimos al menos dos contextos en los que el término es utilizado: el computacional y el comunicacional. Sin embargo, la generalidad, la vaguedad y la aplicabilidad del concepto todavía es muy amplia en este nivel. Se gana riqueza y robustez conceptual una vez que el concepto es interpretado y tal como mostramos y expusimos, existen al menos tres interpretaciones del concepto de información, todas con sus virtudes y problemas para dar cuenta del amplio abanico de situaciones y usos en los que el concepto está involucrado.

Desde el lenguaje cotidiano hasta la mecánica cuántica, el concepto de información ha ganado riqueza, precisión y variedad, a la vez que -visto desde un punto de vista general- se ha vuelto más universal e inasible al análisis filosófico y la elucidación conceptual. Obtener una única definición, filosóficamente rica y sustancial a la cual los 
más variados y disimiles sentidos se refieran, parece una meta cada vez más lejana e inútil. Esperamos que el trabajo haya sugerido al lector que el primer paso acertado a la hora de pensar el concepto de información sea el de aceptar su pluralidad y plurivocidad.

\section{Agradecimientos}

El presente trabajo ha sido realizado gracias al apoyo del subsidio PICT-2014-2812 de la Agencia Nacional de Promoción Científica y Tecnológica (Argentina).

\section{Referencias}

Adrian's, P. (2013). Information. En E. N. Zalta (ed.), The Stanford Encyclopedia of Philosophy, URL = http://plato. stanford.edu/archives/fall2013/entries/ information/

Adriaans, P. \& van Benthem, J. (2008). Handbook of Philosophy of Information. Amsterdam, Oxford: Elsevier.

Bar-Hillel, Y. (1964). Language and Information: Selected Essays on Their Theory and Application. Reading, Mass: AddisonWesley.

Bar-Hillel, Y. \& Carnap, R. (1953). Semantic Information. The British Journal for the Philosophy of Science, 4:147-57.

Barwise, J. \& Seligman, J. (1997). Information Flow: The Logic of Distributed Systems. Cambridge: Cambridge University Press.

Bell, David (1957). Information Theory and its Engineering Applications. London: Pitman \& Sons.

Bergstrom, C. y Rosvall, M. (2011). The transmission sense of information. Biology \& Philosophy, 26: 159-176.

Burnham, K. \& Anderson, D. (1998). Model selection and multimodel inference: a practical information-theoretic approach. New York: Springer.

Chaitin, G. (1966). On the Length of Programs for Computing Binary Sequences. Journal of the Association for Computing Machinery, 13: 547-569.

Cover, T. \& Thomas, J. (1991). Elements of Information Theory. New York: John Wiley \& Sons.

Davies, P. (2014). Universe from bit. En Information and the Nature of Reality, Paul Davies y Niels Gregersen (eds), Cambridge: Cambridge University Press, 65-91.

Devlin, K. J. (1991). Logic and Information. Cambridge: Cambridge University Press.

Dretske, F. (1981). Knowledge \& the Flow of Information. Cambridge MA: MIT Press.Dodig-Crnkovi 2005

Duwell, A. (2008). Quantum Information Does Exist. Studies in History and Philosophy of Modern Physics, 39: 195-216.
Fetzer, J. H. (1990), Artificial Intelligence: Its Scope and Limits, Dordrecht, The Netherlands: Kluwer Academic Publishers.

Fetzer, J. H. (2004). Information: Does It Have to Be True? Minds and Machines, 14(2): 223-229.

Fisher, R. (1925). Theory of Statistical Estimation. Proceedings of the Cambridge Philosophical Society, 22: 700-725.

Floridi, L. (2003). Two Approaches to the Philosophy of Information. Minds and Machines, 13(4): 459-469.

Floridi, L. (2015). The Ethics of Information. Oxford: Oxford University Press

Floridi, L. (2016). "Semantic Conceptions of Information". En The Stanford Encyclopedia of Philosophy, Edward N. Zalta (ed.), URL = <http://plato.stanford.edu/archives/ spr2016/entries/information-semantic/>.

Godfrey-Smith, P. y Sterelny, K. (2016). Biological Information. Em The Stanford Encyclopedia of Philosophy, Edward N. Zalta (ed.), URL = <http://plato.stanford. edu/archives/ sum2016/entries/information-biological/>.

Jozsa, R. (1998). Quantum information and its properties. En Introduction to Quantum Computation and Information, H.-K. Lo, S. Popescu, y T. Spiller (eds.) Singapore: World Scientific, pp. 49-75.

Kolmogorov, A. (1965). Three Approaches to the Quantitative Definition of Information. Problems of Information Transmission, 1: 4-7

Kolmogorov, A. (1968). Logical Basis for Information Theory and Probability Theory. Transactions on Information Theory, 14: 662-664.

Landauer, R. (1991). Information is Physical. Physics Today, 44: 23-29.

Landauer, R. (1996). The Physical Nature of Information. Physics Letters A, 217: 188-193.

Lloyd, S. (2014). The computational universe. En Information and the Nature of Reality, Paul Davies y Niels Gregersen (eds), Cambridge: Cambridge University Press, 92-103.

Lombardi, O. (2005). Dretske, Shannon's Theory and the Interpretation of Information. Synthese, 144: 23-39

Lombardi, O., Holik, F. and Vanni, L. (2014). What Is Quantum Information?, PhilSci Archive, \#11159.

MacKay, D. (1969). Information, Mechanism and Meaning. Cambridge MA: MIT Press.

Nauta, D. (1972). The Meaning of Information. The Hague: Mouton.

Nielsen, M. \& Chuang, I. (2010). Quantum Computation and Quantum Information. Cambridge: Cambridge University Press. 
Reza, F. (1961). Introduction to Information Theory. New York: McGraw-Hill

Rovelli, C. (1996). Relational Quantum Mechanics. International Journal of Theoretical Physics, 35: 1637-1678.

Schumacher, B. (1995). Quantum coding. Physical Review A, 51: 2738-2747.

Shannon, C. (1948). The mathematical theory of communication. Bell System Technical Journal, 27: 379-423.

Solomonoff, R. (1964). A Formal Theory of Inductive Inference. Information and Control, 7: 1-22, 224-254.

Stonier, T. (1990). Information and the Internal Structure of the Universe: An Exploration into Information Physics. New York-London: Springer.

Stonier, T. (1996). Information as a Basic Property of the Universe. Biosystems, 38: 135-140.
Timpson, C. (2004). Quantum Information Theory and the Foundations of Quantum Mechanics. PhD diss., University of Oxford (quant-ph/0412063).

Timpson, C. (2008). Philosophical Aspects of Quantum Information Theory. En The Ashgate Companion to the New Philosophy of Physics, Dean Rickles (ed.),. Aldershot: Ashgate Publishing, pp. 197-261

Timpson, C. (2013). Quantum Information Theory and the Foundations of Quantum Mechanics. Oxford: Oxford University Press.

Wheeler , J. A. ( 1989 ). Information, physics, quantum: The search for links. Proceedings of the Third International Symposium on the Foundations of Quantum Mechanics (Tokyo), 354.

Wittgenstein, L. (1981). Zettel. Oxford: Blackwell.

Zeilinger, A. (1999). A Foundational Principle for Quantum Mechanics. Foundations of Physics, 29: 631-643. 